Journal of Animal and Veterinary Advances 9 (21): 2738-2747, 2010

ISSN: $1680-5593$

(C) Medwell Journals, 2010

\title{
Establishment and Characteristics of Immortal Goat Endometrial Epithelial Cells and Stromal Cells with hTERT
}

\author{
${ }^{1}$ Yan-Yan Zhang, ${ }^{1}$ Ai-Hua Wang, ${ }^{2}$ Qing-Xia Wu, ${ }^{3}$ Hong-Xia Sheng and ${ }^{1}$ Ya-Ping Jin \\ ${ }^{1}$ Key Laboratory of Animal Reproductive Endocrinology and Embryo Biotechnology of Agriculture, \\ College of Veterinary Medicine, Northwest A and F University, \\ Ministry of China, Yangling 712100, Shaanxi, China \\ ${ }^{2}$ College of Animal Science and Technology, Tibet Agricultural and Animal Husbandry College, \\ Linzhi 860000 , Tibet Autonomous Region, China \\ ${ }^{3}$ Laboratory of Cell Therapy Center, 307 Hospital of PLA, Beijing 100071, China
}

\begin{abstract}
The endometrial cell has important use in study of local endocrine-immunoregulatory of uterus in vitro. However, the primary cells were limited by the scarcity of adequate material and the finite lifespan. To establish immortal endometrial cells, the human Telomerase Reverse Transcriptase (hTERT) gene was introduced into primary goat Endometrial Epithelial Cells (EECs) and Endometrial Stromal Cells (ESCs) and obtained two immortalized cell lines, hTERT-EECs and hTERT-ESCs. After hTERT introduction, the biological characteristics of these cells were detected and compared with the primary cells. The results showed that the immortalized hTERT-EECs and hTERT-ESCs retained common cellular characteristics such as morphology, anchorage requirement, contact inhibition and serum-dependence. Their growth covers accorded to the normal growth regularity. The Keratin and Vimentin were also detected. In addition, these cells possessed normal diploid karyotype, retained responsiveness to sex-steroid hormones and lacked transformed phenotypes on soft agar or in nude mice. In short, the immortalized goat endometrial cell lines (hTERT-EECs and hTERT-ESCs) had been developed what were karyotypically, morphologically and phenotypically similar to the primary parent cells. To date, hTERT-EECs had been passaged for 60 times and hTERT-ESCs for 65 and they would be convenient and consistent resources for in vitro research.
\end{abstract}

Key words: Human Telomerase Reverse Transcriptase (hTERT), immortalization, biological characteristics, endometrial cells, goat, phenotypically

\section{INTRODUCTION}

Uterus is a peculiar immunologic organ because of its function and complex mechanism of action. In gestation period, the uterus ensures the fetus has enough nutrition and would not be rejected by the matrix as an allograft. On the other hand, the uterus also makes the matrix avoid the damage of fetal antigen. Throughout the reproductive process the endometrium plays an important role. The endometrium is a particular tissue characterized by constant and rapid cell proliferation, differentiation and shedding (Satoru et al., 2003). Because the uterus is a primary target of sex steroid in vivo, the proliferative activity of endometrium is exquisitely regulated by the cooperative actions of estrogen and progesterone (Asselin et al., 1996; Wen et al., 2006). For the close relationship with embryonic implantation and pregnant maintenance, the endometrium is very important in the study of reproductive physiology. Cultured endometrial cells in vitro are adequate material to research the cellular mechanisms such as growth and differentiation, the mechanism of ovarian hormone and interaction of uterus and embryo. But the use of cultured cells for in vitro studies is limited by the availability of tissue, difficulties in culturing, and limited life span (Masamune et al., 2003). All of these make studies difficult to undertake and reproduce.

So many efforts had been turned to establish the immortalized cell lines with unlimited replicative potentiality and normal cellular functions (Matsumura et al., 2004; Piao et al., 2005; May et al., 2005; Jin et al., 2006). hTERT is well known to avoid replicative senescence and effectively gives normal cells an unlimited life span in culture without any change in the fundamental cellular characteristics (Graciela et al., 2004; Nakamura et al., 2002). And the transfection of hTERT

Corresponding Author: Ai-Hua Wang, College of Veterinary Medicine, Northwest A and F University, Yangling 712100 , Shaanxi, China 
had established immortalized cell lines in many species (Argyle et al., 2003; Buser et al., 2006; Hombach-Klonisch et al., 2006; Oh et al., 2007). Thus, we tried to establish new goat endometrial cell lines. The primary goat EECs and ESCs were separated and cultured and then the object plasmid, pCI-neo-hTERT was transfected into these cells to obtain immortal clones. The process of immortalization might change the normal cellular karyotypes and functional characteristics (Graciela et al., 2004), so the cells biological characteristics must be detected.

The immortalization of goat EECs and ESCs would permit establishment of continuous cell lines facilitating study of their cell growth, differentiation and function. It would also supply useful material to reconstruct endometrium in vitro and greatly benefit the further study of ovarian hormone functions, embryos implantation and local endocrine-immunoregulation of uterus.

\section{MATERIALS AND METHODS}

Cell culture and immortalization: Primary goat endometrial cells (EECs and ESCs) were isolated from the endometrium of an 8 month old goat as previously described (Johnson et al., 1999) with modifications. In brief, the endometrium was prepared into small tissue blocks and digested by Collagenase $\alpha$ (Gibco, Gaithersburg, $\mathrm{MD}$, USA) for $4 \mathrm{~h}$ at $37^{\circ} \mathrm{C}$. The postdigestive cells suspension was filtered by 200 cell sieve and the filtrate was centrifuged for $5 \mathrm{~min}, 500 \mathrm{rpm}$. After the low-speed centrifugalization, primary EECs and ESCs were initially separated because of their different settling velocity. EECs were pelleted to the bottom of the centrifuge tube on the contrary, ESCs were in the upper suspension. They were further purified by naturalsettlinglow centrifugalization for 3-5 times. Obtained EEC and ESC cells were cultured in DMEM/F-12 (DF12, Sigma, St. Louis, Mo, USA) media enriched with $10 \%(\mathrm{v} / \mathrm{v})$ fetal bovine serum (FBS, Gibco, Gaithersburg, MD, USA) and $100 \mathrm{IU}$ penicillin-streptomycin.

The cells were transfected with the pCI-neo-hTERT plasmid (presented by Prof. Wang Huayan, Northwest A and F University, Yangling, China) using Suohuasofast transfection kit (Sunma, Xiamen, China) according to the instructions. When the infected cells grew to $80 \%$ confluence, they were selected by $600 \mathrm{\mu g} \mathrm{mL}^{-1}$ neomycin (G418, Promega, WI, USA) for 2 weeks. Cell clones resisted G418 were purified and expanding cultured (Putmann et al., 2005).

RT-PCR detection for hTERT gene: The expression of hTERT mRNAs was analyzed by RT-PCR. The total cell
RNA was isolated using Trizol Reagent (Invitrogen, CA, USA) utilizing the manufacturer's protocol followed by reverse transcription with First Strand cDNA synthesis kit (MBI Fermentas, MD, USA). The primers of hTERT for PCR were 5'-TATGCCGTGGTCCAGAAGG-3' (forward) and 5'-GCGTGGGTGAGGTGAGGTGT-3' (reverse). The aim gene fragment was $410 \mathrm{bp}$. The PCR amplification used $50 \mu \mathrm{L}$ reaction system according to the instruction manual of Taq polymerase (Takara, Dalian, China) and the conditions consisted of pre-denaturation at $94^{\circ} \mathrm{C}$ for $30 \mathrm{sec}$ followed by 35 cycles of denaturation $30 \mathrm{sec}$ at $94^{\circ} \mathrm{C}$, annealing at $55^{\circ} \mathrm{C}$ for $30 \mathrm{sec}$ and extension at $72^{\circ} \mathrm{C}$ for $30 \mathrm{sec}$, at last extension at $72^{\circ} \mathrm{C}$ for $10 \mathrm{~min}$. The PCR productions was tested by $1 \%$ agarose gel electrophoresis and stained with ethidium bromide (EB, Sigma, MO, USA). The results were observed under UV transilluminator (Syngene, MD, USA).

Detection of telomerase activity by TRAP-ELISA: The telomerase activity was detected by a TRAP-ELISA kit (Roche, Mannheim, Germany) following the manufacturer's instructions. About $1 \times 10^{6}$ cells were collected and washed. After centrifuged the cells pellet was resuspended in lysis buffer and incubated in an ice bath for $30 \mathrm{~min}$. The lysate was centrifuged at $14000 \mathrm{rpm}$ at $4^{\circ} \mathrm{C}$ for $20 \mathrm{~min}$ and the supernatant was used for Telomeric Repeat Amplification Protocol (TRAP). The PCR amplification conditions were: $94^{\circ} \mathrm{C}$ for $2 \mathrm{~min}$, 35 cycles of $94^{\circ} \mathrm{C}$ for $30 \mathrm{sec}, 48^{\circ} \mathrm{C}$ for $30 \mathrm{sec}$ and $72^{\circ} \mathrm{C}$ for $90 \mathrm{sec}$, finally $72^{\circ} \mathrm{C}$ for $5 \mathrm{~min}$. The PCR productions were detected by ELISA and the Optical Densities (OD) at $450 / 630 \mathrm{~nm}$ were read using a microplate reader (BioRad, Tokyo, Japan). The sample whose OD was $>2.1$ times of the negative control's was identified as positive one for telomerase activity.

Identification of Keratin and Vimentin with immunohistochemistry: When the cells grew up to monolayer on culture plate, hTERT-EECs, EECs, hTERTESCs and ESCs were fixed by 95\% alcohol (v/v). Subsequently, the identification was carried with the introduction of SABC immunocytochemical staining kits (Maxim, CA, USA). The first antibody was separately mouse antibodies against Keratin and Vimentin (Boster, Wuhan, China). In negative control of hTERT-EECs and EECs, PBS was used as the first antibody.

Growth curve: Growth curve was detected by Methyl Thiazolyl Tetrazolium (MTT) assay described by Kasugai et al. (1990). hTERT-EECs, EECs 
$\left(1 \times 10^{5}\right.$ cells $\left.\mathrm{mL}^{-1}\right)$ and hTERT-ESCs, ESCs $\left(1 \times 10^{4}\right.$ cells $\mathrm{mL}^{-1}$ ) were seeded into 96-well plates, respectively and cultured at $37^{\circ} \mathrm{C}$ and $5 \% \mathrm{CO}_{2}$. From the second day, $20 \mu \mathrm{L}$ of MTT solution ( $5 \mathrm{mg} \mathrm{mL}^{-1}$, Amresco, Solon, USA) was added to the triplicate wells of the cells and incubated for $4 \mathrm{~h}$. After removed the medium, $150 \mu \mathrm{L}$ of DMSO was added and shook for $10 \mathrm{~min}$. The $\mathrm{OD}$ values were measured at $570 \mathrm{~nm}$ for 8 days continuously and the growth curves were organized.

Soft agar cloning test: If hTERT-EECs and hTERT-ESCs had suspension growth was investigated by soft agar cloning test. These cells $\left(5 \times 10^{5}\right.$ cells per well) were in triplicate plated in $0.5 \mathrm{~mL}$ culture medium containing $0.3 \%$ $(\mathrm{w} / \mathrm{v})$ agar above a previously solidified $0.7 \%(\mathrm{w} / \mathrm{v})$ bottom agar, respectively (Oh et al., 2007). After 2 weeks of incubation at $37^{\circ} \mathrm{C}$ in air with $5 \% \mathrm{CO}_{2}$, cell colonies were observed under microscope. ESCs and EECs were negative controls and HeLa cell was positive.

Subcutaneous tumorigenicity assay in nude mice: The nude mice (male, 6 week old Balb/c nu $/ \mathrm{nu}^{-}$) were used to determine cells tumorigenicity. hTERT-EECs and hTERTESCs were suspended in DF12 without FBS at a density of $1 \times 10^{6}$ cells $\mathrm{mL}^{-1}$ and subcutaneously injected $0.1 \mathrm{~mL}$ at the flank of each mouse. The group injected with Hybridoma SP $2 / 0$ cell was positive control. Each cell was injected to three nude mice and the mice were monitored for 2 months (Satoru et al., 2003). The nude mice were bought from National Rodent Laboratory Animal Resources, Shanghai Branch (NLARSH) and raised in The Fourth Military Medical University. All animals received humane care in compliance with the Animal Care and Use Guidelines of American National Institutes of Health and were approved by Animal Care and Use Committee of Northwest A and F University.

Effection of sex hormones: To investigate the response of hTERT-ESCs and hTERT-EECs to sex hormones in vitro, $\beta$-estradiol and progesterone $\left(\mathrm{E}_{2}\right.$ and $\left.\mathrm{P}_{4}\right)$ were diluted in cell medium to different concentration according to Table 1. hTERT-ESCs $\left(1 \times 10^{4}\right.$ cells $\left.\mathrm{L}^{-1}\right)$ and hTERT-EECs $\left(1 \times 10^{4}\right.$ cells $\left.\mathrm{L}^{-1}\right)$ were, respectively seeded into 96-well plates and cultured with DF12 mediums contained different concentration of $\mathrm{E}_{2}$ or/and $\mathrm{P}_{4}$. The growth curves of these groups were detected by MTT assay as above.

Table 1: The treatment of $\mathrm{E}_{2}$ and $\mathrm{P}_{4}$ to hTERT-ESCs and hTERT-EECs $\left(\mathrm{nmol} \mathrm{L}{ }^{-1}\right.$ )

\begin{tabular}{llrrrr}
\hline Treatment groups & 1 & 2 & 3 & \multicolumn{1}{c}{4} & \multicolumn{1}{c}{5} \\
\hline $\mathrm{E}_{2}$ & 0 & 0 & 10 & 100 & 100 \\
$\mathrm{P}_{4}$ & 0 & 100 & 100 & 0 & 10 \\
\hline
\end{tabular}

Cell cycle: The cells $\left(1 \times 10^{6}\right.$ cells $\left.\mathrm{mL}^{-1}\right)$ were collected and washed twice with PBS and fixed in $70 \%(\mathrm{v} / \mathrm{v})$ ethanol at $4^{\circ} \mathrm{C}$ for at least $20 \mathrm{~min}$. Then the fixed cells washed and stained with $18 \mu \mathrm{L} \mathrm{mL}{ }^{-1} \mathrm{PI}$ in the presence of $40 \mu \mathrm{g} \mathrm{mL}^{-1}$ RNase A. The phase distribution in the cells cycle was analyzed by flow cytometry (Zhang et al., 2005; Chen et al., 2006).

Chromosomal analysis: When the cells grew to confluence, new DF1 2 medium contained $0.1 \%$ colchicine was changed. After incubating for $4 \mathrm{~h}$ at $37^{\circ} \mathrm{C}$, the cells were colleted by trypsinization-centrifugation and resuspended in prewarmed $8 \mathrm{~mL} \mathrm{KCl}$ solution $(0.075 \mathrm{M}$ ) incubating for $30 \mathrm{~min}$ at $37^{\circ} \mathrm{C}$. About $1 \mathrm{~mL}$ mixture of methanol: acetic acid (3:1) was added to pre-fixed cells and then the cells was centrifuged and fixed twice by $5 \mathrm{~mL}$ methanol: acetic acid (3:1) for $20 \mathrm{~min}$ at room temperature. Finally, bits of this suspension were dropped on chilled glass slides from about $30 \mathrm{~cm}$ height and stained with Giemsa after air dry. The chromosomal numbers of the cells were determined (Chen et al., 2008).

Statistical analysis: All the tests were repeated three times and the results were expressed as mean \pm standard deviation (mean $\pm \mathrm{SD}$ ). Differences between them were evaluated by Least Square Method in SPSS software package (Ver.13.0). The $\mathrm{p}$ value of $<0.05$ was estimated statistical significant.

\section{RESULTS AND DISCUSSION}

Cell culture and transfection: The transfected cells appeared similar to the primary ones and had no morphological change (Fig. 1), hTERT-ESCs presented fibroblast-like and hTERT-EECs retained cobblestone appearance. The cells grew as confluent monolayers with contact inhibition and serum-dependence.

RT-PCR detection for hTERT gene: The expression of hTERT gene in transferred cells was analyzed by RT-PCR (Fig. 2). As expected, hTERT-ESCs and hTERT-EECs were both obtained the aim gene segment as well as the plasmid pCI-neo-hTERT. On the contrary, the primary cells were not amplified.

Detection of telomerase activity by TRAP-ELISA: The telomerase activity was measured by TRAP-ELISA assay and the result showed that the ratio of $\mathrm{OD}_{450 / 630}$ between hTERT-ESCs and negative control was $4.28(>2.1)$ and that of hTERT-EECs and negative control was $4.66(>2.1)$. 

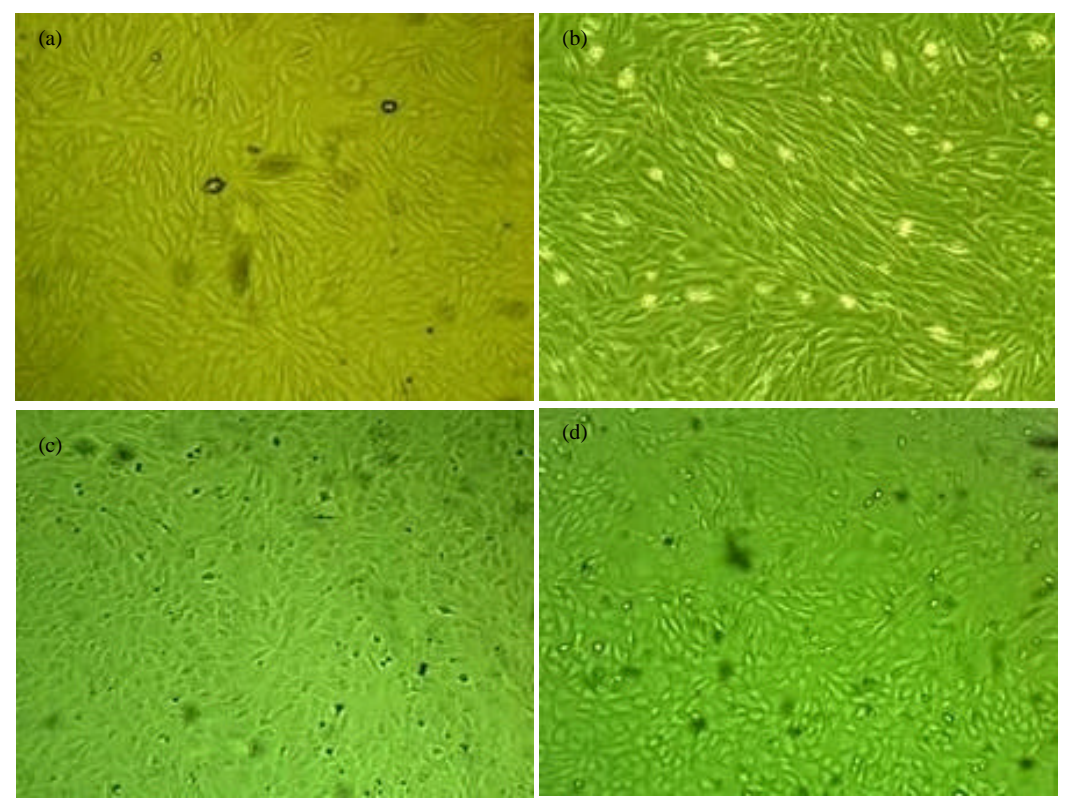

Fig. 1: Cultured goat endometrial cells before and after transfection (100×), the transfected cells, hTERT-ESCs and hTERT-EECs grew well compared to the primary cells and the morphological characteristics were normal. a) Primary ESCs; b) hTERT-ESCs; c) Primary EECs and d) hTERT-EECs

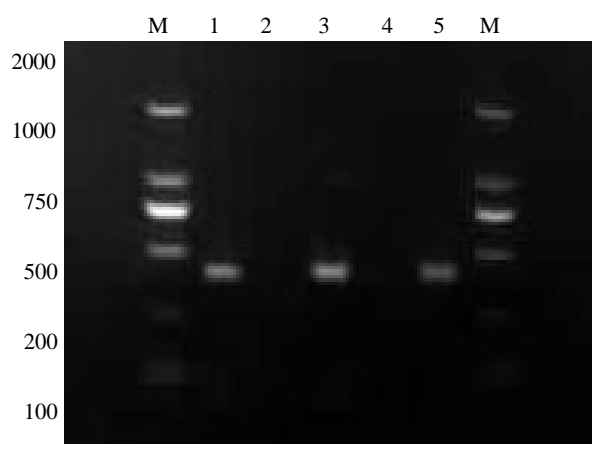

Fig. 2: RT-PCR amplification for hTERT gene, according to the hTERT gene sequence, a pair of primer was designed and the aim fragment had $410 \mathrm{bp}$. The RT-PCR amplification showed that the transfected cells both obtained aim fragment as well as the positive plasmid while the primary cells hadn't, $\mathrm{M}$ : stands for 1000 bp DNA marker, 1: pCI-neohTERT plasmid, 2: EECs, 3: hTERT-EECs, 4: ESCs, 5: hTERT-ESCs

While ESCs/negative control was $1.04(<2.1)$ and EECs/negative control was $0.96(<2.1)$ (Fig. 3). Thus the transfected cells had telomerase activity and the primary cells had no telomerase activity.

Identification of Keratin and Vimentin with immunohistochemistry: Immunohistochemistry staining

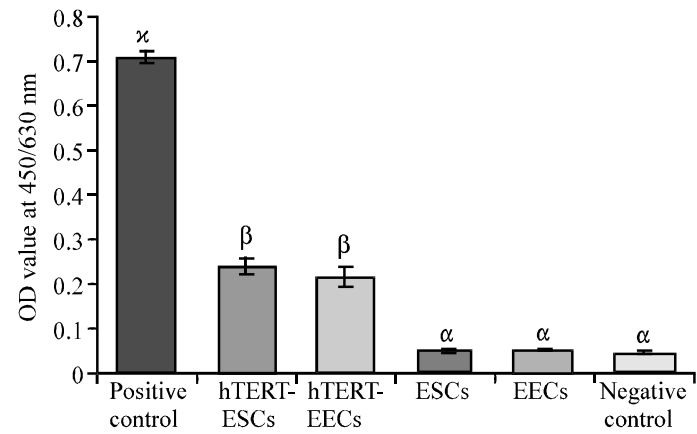

Fig. 3: Detection of telomerase activity by TRAP-ELISA. Telomerase activity in transfected and primary cells were detected by TRAP-ELISA assay. The negative control and positive control were the TRAP-ELISA kit own. The result indicated the primary cells had no telomerase activity, on the contrary, hTERT-EECs and hTERT-ESCs showed telomerase activity

was used to identify the epithelial cells and fibroblast cells with the keratin antibody and the Vimentin antibody. The cytoplasm of positicve cells was stained dark brown and staining was especially strong near the nuclear while the negative ones didn't show this color (Fig. 4).

The results showed that hTERT-ESCs were Vimentinpositive and keratin-negative like ESCs which indicated hTERT-ESCs remained fibroblasts. Similarly 

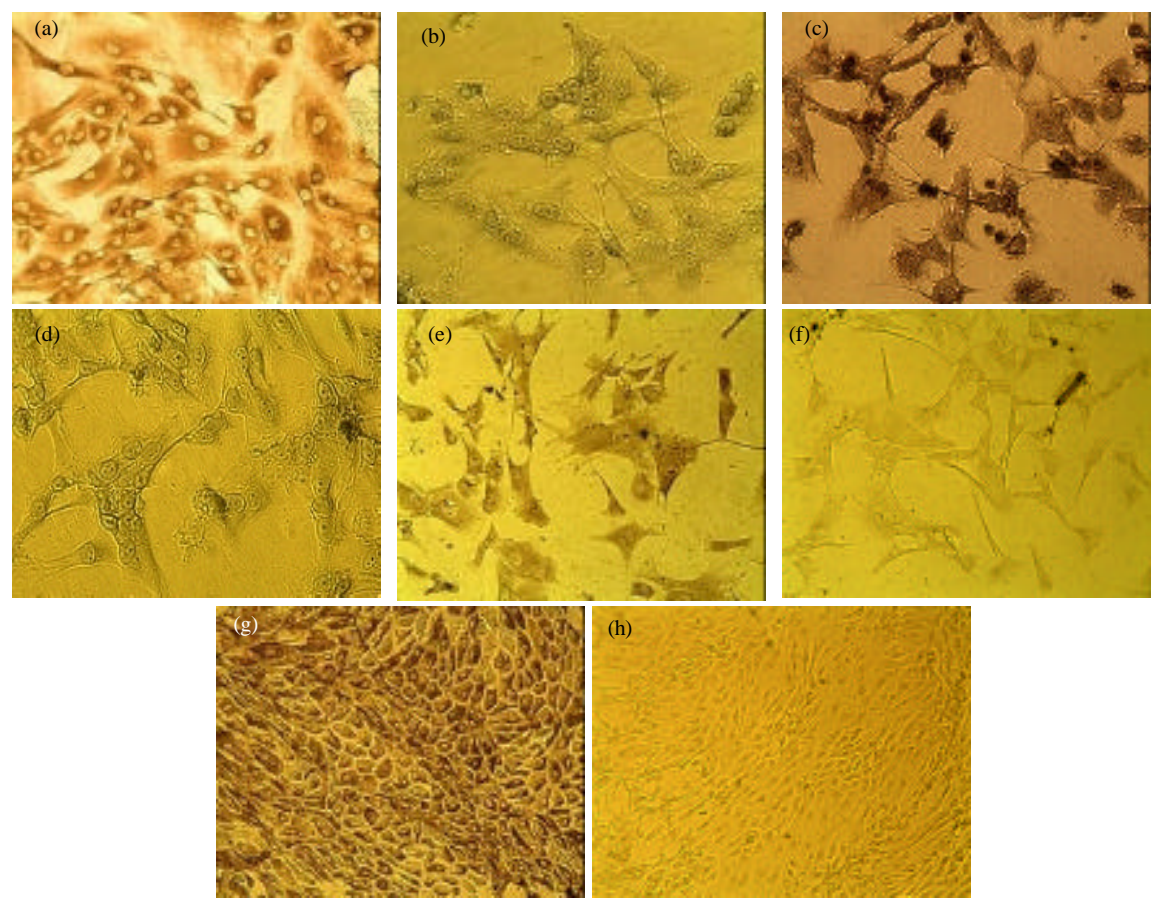

Fig. 4: Immunohistochemistry (A-G, 200×; H, 100×), the cells were detected for Vimentin and Keratin and then they showed nomal immunohistochemical characteristics: hTERT-ESCs and ESCs were Vimentin-positive and Keratinnegative while hTERT-EECs and EECs were Keratin-positive. a) hTERT-ESCs for Vimentin; b) hTERT-ESCs for Keratin; c) ESCs for Vimentin; d) ESCs for Keratin; e) EECs for Keratin; f) EECs, PBS control; g) hTERT-EECs for Keratin and h) hTERT-EECs, PBS control

hTERT-EECs and EECs were also stained by the keratin antibody; meanwhile the negative control group was keratin-negative. These suggested that hTERT-EECs were retained epithelial characteristics.

Growth curve: Figure 5 compared the proliferation of primary and immortalized cells. The growths of primary and immortalized cells were basically similar and accorded with common growth regularity. At the first 2 days, cells were in latency stage and grew slow following by rapid proliferation form 3 days.

The peak arrived at 4 or 5 days and then decreased gradually. Analyzed form the peak, the immortalized cells arrived earlier and numerically larger than primary ones. This meant that cells after transfection had vigorous proliferation.

The primary cells could not be cultured $>10$ passages whereas the immortalized one continued to divide. Up to today, hTERT-EECs had been cultured for 60 passages and hTERT-ESCs for 65.

Soft agar cloning test: To determine whether hTERTESCs and hTERT-EECs showed oncogenic transformation we tested the cells ability of colony formation in soft agar.



Fig. 5: Growth curves, the growth curve was detected by MTT assay. Data showed as mean $\pm \mathrm{SD}(\mathrm{n}=3)$. It could see that the transfected cells accorded to the common growthy regularity moreover, they had more vigorous growing ability than the primary ones. a) hTERT-ESCs and ESCs and b) hTERTEECs and EECs 
The hele cell line was used as the positive control. It showed that none of the cells (hTERT-ESCs, hTERTEECs, ESCs and EECs) formed colonies in soft agar except the hale cells after 2 weeks.

Subcutaneous tumorigenicity assay in nude mice: The nude mice were applied to further test for tumorigenicity. All animals those had been implanted with hTERT-ESCs, hTERT-EECs, ESCs and EECs lived healthy and no tumors formed during the 2 months.

In contrast SP $2 / 0$ cells developed tumors from day 7 after implantation. The diameter of the tumor grew to $4 \mathrm{~cm}$ at day 28. The mice had bad mental status and died at day 35 .

Effection of sex hormones: The result indicated that $\mathrm{E}_{2}$ and $\mathrm{P}_{4}$ could influence the proliferation of hTERT-EECs and hTERT-ESCs. Comparing with the growth curve of control group (Fig. 6) in groups of $100 / 0 \mathrm{nmol} \mathrm{L}^{-1}$ and $100 / 10 \mathrm{nmol} \mathrm{L}^{-1} \mathrm{E}_{2} / \mathrm{P}_{4}$ the $\mathrm{OD}$ values were higher than the others distinctly.

The $0 / 100$ and $10 / 100 \mathrm{nmol} \quad \mathrm{L}^{-1} \quad \mathrm{E}_{2} / \mathrm{P}_{4}$ made proliferation slowly and the $\mathrm{OD}$ values were obviously lower than other groups. Further comparing the OD values in the 5 th day, significant difference $(\mathrm{p}<0.05)$ presented between treatment groups of $\mathrm{E}_{2} / \mathrm{P}_{4}$ and no treatment group (Table 2). Those showed that $\mathrm{E}_{2}$ could promote the proliferation of hTERT-ESCs and hTERTEECs but $\mathrm{P}_{4}$ inhibited them.

Cell cycle: Looking from the distribution of cell cycle (Fig. 7), the percentage of hTERT-EECs in dormant phase (G1) was $52.6 \%$, lower than EECs $(57.3 \%)$ and that in proliferative phase ( $+\mathrm{G} 2$ ) was $47.4 \%$, higher than EECs $(42.6 \%)$. Similarly, the ratio of hTERT-ESCs in G1 was $41.6 \%$ lower than ESCs $(52.1 \%)$ and proliferative cells (S+G2) had 58.42\% higher than ESCs (47.89\%). These displayed that the immortalized cells had greater proliferation activity than primary ones.

The Gl peak was also named diploid peak. DNA content of hTERT-EECs was 82.5 (mean G1) and that of EECs was 73.1. So the DNA Index (DI) of hTERT-EECs was around $1(82.5 / 73.1)$, the same as hTERT-ESCs $(76.5 / 60.9)$. The result indicated that both the hTERTEEC and hTERT-ESC were diploid cells. Moreover, there had no any aberrant and additional peak before the G1 peak of all the cells that meant the cells had no apoptosis.

Chromosomal analysis: The result indicated that the chromosomes were all telocentric ones (Fig. 8). The chromosome number was $2 n=60$ among which 29 pairs were autosomes and 1 pair was allosome. And the allosome pair was XX in female and was the second pair of big telomeric ends of chromosomes. This result corresponded with goat's chromosomes characteristics (Chen et al., 2008).

According to current studies, Telomerase Reverse Transcriptase (TERT) had been found that had more advantages than other factors in inducing cells to immortalization (Graciela et al., 2004; Hong et al., 2007). Many studied (Guilleret et al., 2002) manifested that the immortal cells mediated by TERT had the characteristics of normal cells (vigor, karyotype, contact inhibition

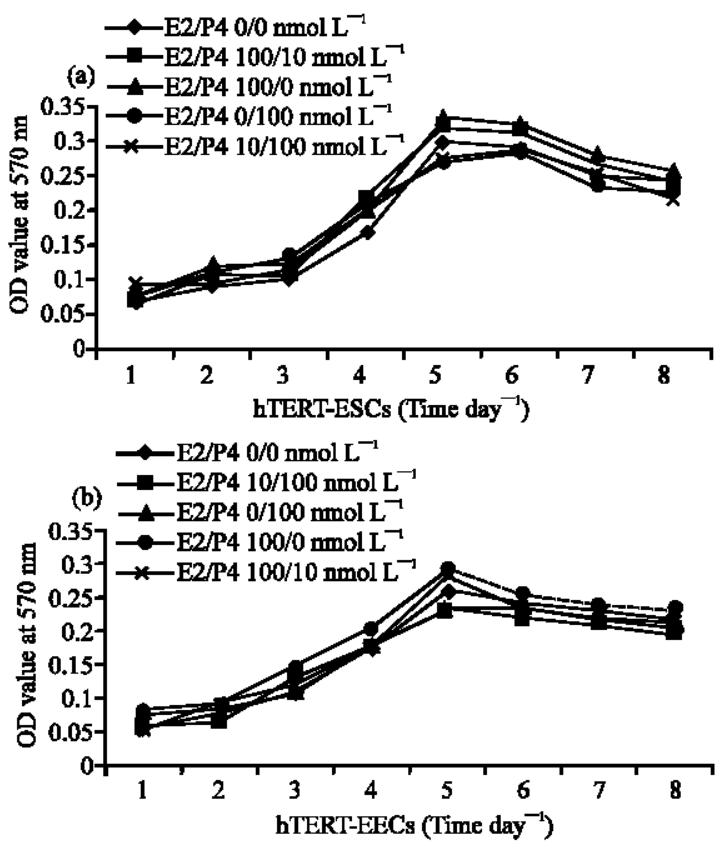

Fig. 6: Growth curve under the effection of sex hormones $\left(\mathrm{E}_{2}\right.$ and $\mathrm{P}_{4}$ ) detected by MTT test, different levels of $\mathrm{E}_{2}$ or/and $\mathrm{P}_{4}$ were added in DF12, the curves showed $100 \mathrm{nmol} \mathrm{L}{ }^{-1} \mathrm{E}_{2}$ could promoted cells proliferation and $100 \mathrm{nmol} \mathrm{L}^{-1} \mathrm{P}_{4}$ inhibited it. The data are means \pm SD of three independent experiments. a) hTERT-EECs and b) hTERT-ESCs

Table 2: OD values (5th day) of hTERT-EECs and hTERT-ESCs treated by different $\mathrm{E}_{2} / \mathrm{P}_{4}$ level $\left(\mathrm{nmol} \mathrm{L}^{-1}\right)$

\begin{tabular}{lccccc}
\hline E $/ \mathrm{P}_{4}$ groups & $0 / 0$ & $10 / 100$ & $0 / 100$ & $100 / 10$ & $100 / 0$ \\
\hline hTERT-EECs & $0.259 \pm 0.006$ & $0.232 \pm 0.014^{*}$ & $0.235 \pm 0.006^{*}$ & $0.282 \pm 0.005^{*}$ & $0.291 \pm 0.018^{*}$ \\
hTERT-ESCs & $0.294 \pm 0.006$ & $0.271 \pm 0.019^{*}$ & $0.266 \pm 0.008^{*}$ & $0.317 \pm 0.006^{*}$ & $0.328 \pm 0.01^{*}$ \\
\hline
\end{tabular}

The data with * means different significantly compared with $0 / 0 \mathrm{E} 2 / \mathrm{P} 4$ group in the same line $(\mathrm{p}<0.05)$ 



Fig. 7: Cell cycle and DNA content analysis by FCM, cells are eugenic growth and division, they concentrate on G1 and $\mathrm{S}$ period of cell cycle for the most part. There had no apoptotic peak in front of G1. The transfected cells in G1 phase were less and those in S/G2 phase were higher than primary ones meaning the transfected cells had more vigorous proliferation. a) EECs; b) hTERT-EECs; c) ESCs and d) hTERT-ESCs
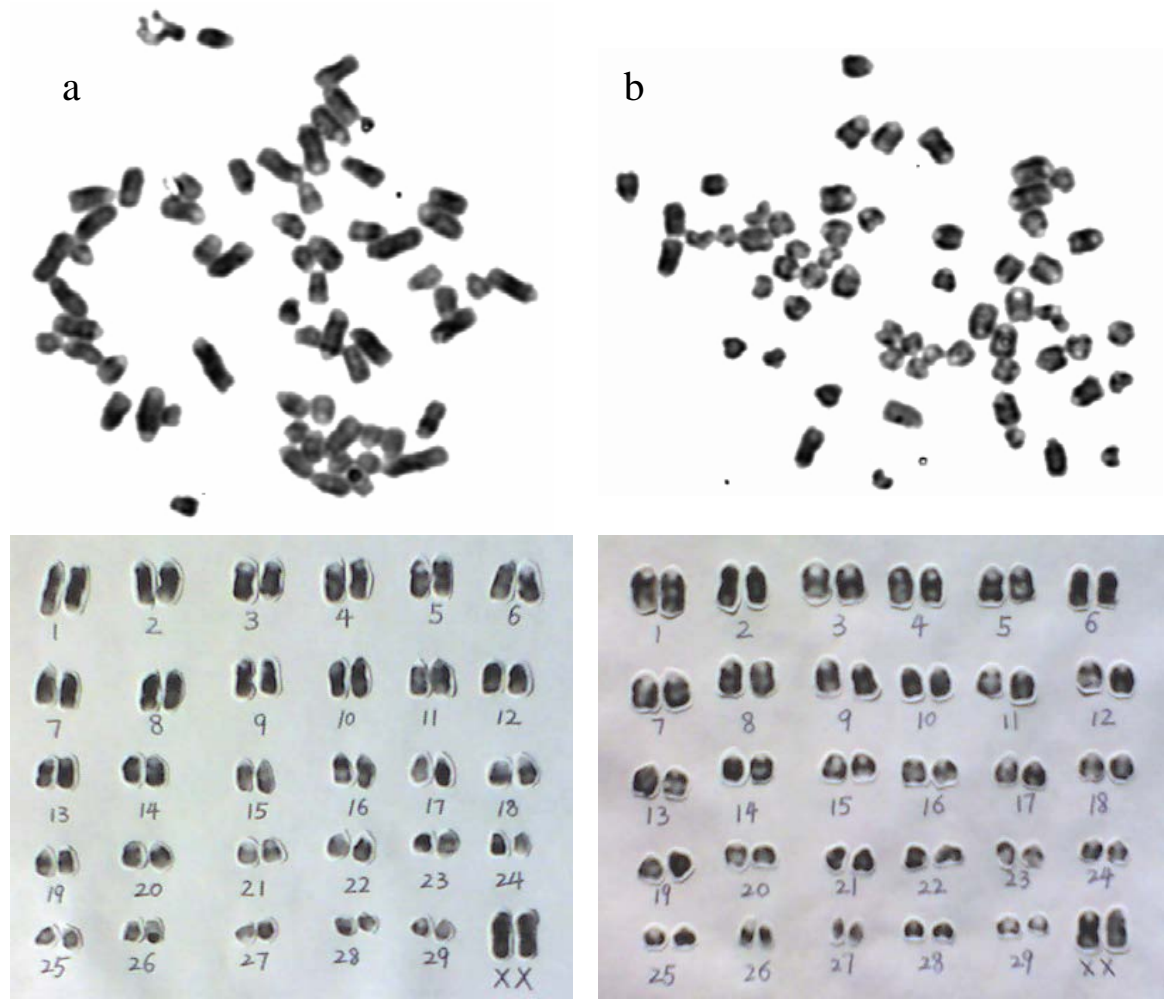

Fig. 8: Cell chromosomes, the cell chromosomes were normally contained 30 pairs of acrocentric ones and no chromosome disorder. a) hTERT-EECs and b) hTERT-ESCs 
anchoring dependency, no carcinogenicity and soft agar cloning ability) without transformation. Moreover, they possess immortalization characteristic actually like embryonic stem cells. The human Telomerase Reverse Transcriptase (hTERT) is the most common choice and numerous immortalized cell lines have been established from various domestic animals such as bovine, equine, ovine, avian, canine and porcine (Gillio-Meina et al., 2000; Argyle et al., 2003; Cui et al., 2003; You et al., 2004; Jin et al., 2006; Christman et al., 2006).

Here, firstly reported the establishment of immortalized cells derived from goat endometrium by hTERT as far as know. Although, Hande (2004) reported that the cell transfected with hTERT could remain natural Phenotype and grow without limition another study found that hTERT gene led in normal cell might cause over-expression of oncogene protein and produce canceration finally (Pihan et al., 2003). Therefore it was necessary to confirm that the cells transfected with hTERT preserved normal phenotype and characteristics but were no transformed ones.

Contrarily, the transformed cell was caused by outside Physic-chemical factor or virus and located on transient state between normal cell and tumour cell. The transformed cell has not only immortality but other conversion characteristics what partly or totally differ from the normal cell. For example the morphocytology and karyotype showing mainly in chromosome numbers and structure would change (Li et al., 2008). Moreover, the transformed cell has tumorigenesis and suspension growth abilities with serum-dependent reduction and loss of contact inhibition. In this study, immortal goat endometrial cell lines (hTERT-ESCs and hTERT-EECs) were established and a series of detections (tumorigenicity assay, suspension growth, soft agar cloning test and chromosomal analysis) were applied to determine the characteristics of the cells obtained. The results demonstrated that hTERT-ESCs and hTERT-EECs had the characteristics of nomal cells such as cells contact-inhibition, serum-dependent growth and normal karyotype and no abilities of oncogenicity and suspension growth. All these evidences verified that hTERT-ESCs and hTERT-EECs were immortalized cells and had no conversion characteristics.

The immunohistochemistry test of vimentin and keratin showed hTERT-ESCs was vimentin-positive and keratin-negative while hTERT-EECs was keratin-positive which agree with non-transformed ESCs and EECs, respectively which indicated hTERT-ESCs and hTERT-EECs possessed the properties of ordinary cell phenotype. The growth curve also verified the cells transfected with hTERT had common growth features. The cells grew well and the growth activities were stronger than non-transformed cells, this maybe because the introduction of hTERT activated telomerase and changed some regulatory factors of cell cycle. Furthermore, we found there had almost no plateau in the growth curve of hTERT-EECs, the cells were easy to assemble and die if not be passaged in time. The endometrium was regulated by steroid hormones, ovary Estrogen $\left(\mathrm{E}_{2}\right)$ and Progestin $\left(\mathrm{P}_{4}\right) . \mathrm{E}_{2}$ could make endometrial proliferation and $\mathrm{P}_{4}$ enhanced endometrial secretes activity; the combination of $\mathrm{E}_{2}$ and $\mathrm{P}_{4}$ caused endometrial cell division and proliferation abundantly after ovulation which lead to further cells decidua reaction and development of deciduas (Qian, 2003). Studies have shown $\mathrm{E}_{2}$ could elevate the vitality of telomerase and increase the expression of hTERT. Also $\mathrm{E}_{2}$ could increase cell division and proliferation and lessen apoptosis. By contraries $\mathrm{P}_{4}$ could raise cell apoptosis but could not alter the activity of cell telomerase (Cui et al., 2004). $\mathrm{P}_{4}$ inhibited cells proliferation and dedicated to the cells decidualization (Frederick et al., 2003; Qian, 2003). In this research, hTERT-ESCs and hTERT-EECs remained response to ovarian hormone. $\mathrm{E}_{2}$ could boost the cells proliferation distinctly and contrarily $\mathrm{P}_{4}$ inhibited it obviously that corresponded with Satoru et al. (2003) and Cui et al. (2004).

\section{CONCLUSION}

In the study, two immortalized goat endometrial cell lines (hTERT-ESCs and hTERT-EECs) had been established which were karyotypically and phenotypically similar to the primary parent cells and displayed similar phenotypic characteristics, respond to hormone stimulation similar to cultured primary stromal cells, no chromosomal abnormalities and lack transformed phenotypes on soft agar or in nude mice. These immortal cell lines should prove to be invaluable tools for consistent in vitro research such as the research of stratified endometrium, the mechanism of embryo implantation, hormone functions and endometrial biology.

\section{ACKNOWLEDGEMENTS}

Thanks Prof. Wang Huayan for the gift of pCI-neohTERT plasmid. The research was supported by the National Natural Science Fund Project of China (grant numbers 39770545) and Research Fund for the Doctoral Program of Higher Education of China (grant number 200807120022). 


\section{REFERENCES}

Argyle, D., V. Ellsmore, E.A. Gault, A.F. Munro and L. Nasir, 2003. Equine telomeres and telomerase in cellular immortalization and ageing. Mech. Ageing Dev., 124: 759-764.

Asselin, E., A.K. Goff, H. Bergeron and M.A. Fortier, 1996. Influence of sex steroids on the production of prostaglandins $\mathrm{F}_{2 \alpha}$ and $\mathrm{E}_{2}$ and response to oxytocin in cultured epithelial and stromal cells of the bovine endometrium. Biol. Reprod., 54: 371-379.

Buser, R., R. Montesano, I. Garcia, P. Dupraz and M.S. Pepper, 2006. Bovine microvascular endothelial cells immortalized with human telomerase. J. Cell. Biochem., 98: 267-286.

Chen, J., H. Peng, S. Pu and Y. Guo, 2006. Apoptosis induced by ginsenoside $\operatorname{Rg} 3$ in a human bladder carcinoma cell line. Chinese J. Clin. Oncol., 3: 283-287.

Chen, W.P., S.J. Zhao, Y.Z. Pang, Y.B. Yang and J.Y. Bai, 2008. Analysis of chromosome karyotype in funiu white goat. Heilongjiang Anim. Sci. Vet. Med., 5: 13-15.

Christman, S.A., B.W. Kong, M.M. Landry, H. Kim and D.N. Foster, 2006. Contributions of differential p53 expression in the spontaneous immortalization of a chicken embryo fibroblast cell line. BMC Cell Biol., 7: 27-27.

Cui, W., D. Wylie, S. Aslam, D. Dinnyes, T. King, I. Wilmut and A.J. Clark, 2003. Telomeraseimmortalized sheep fibroblasts can be reprogrammed by nuclear transfer to undergo early development. Biol. Reprod., 69: 15-21.

Cui, Y.L., J. Ni and G. Y. Liu, 2004. Effect of estrogen and progestin on telomerase activity and cell cycle in endometrial carcinoma cells. Cancer Res. Prevention Treatment, 31: 403-405.

Frederick, S., G. Krikun, R. Caze, M. Rahman and C.J. Lockwood, 2003. Progestin-regulated expression of tissue factor in decidual cells: Implications in endometrial hemostasis, menstruation and angiogenesis. Steroids, 68: 849-860.

Gillio-Meina, C., C.L. Swan, N.K. Crellin, D.M. Stocco and P.J. Chedrese, 2000. Generation of stable cell lines by spontaneous immortalization of primary cultures of porcine granulosa cells. Mol. Reprod. Dev., 57: $366-374$.

Graciela, K., G. Mor, A. Alvero, S. Guller and F. Schatz et al., 2004. A novel immortalized human endometrial stromal cell line with normal progestational response Endocrinol., 145: 2291-2296.
Guilleret, I., Y. Pu, G. Fabienne, B. Richard, B.T. Fred and B. Jean, 2002. Hypermethylation of the human telomerase catalytic subunit (hTERT) gene correlates with telomerase activity. Int. J. Cancer, 101: 335-341.

Hande, M.P., 2004. DNA repair factors and telomerechromosome integrity in mammalian cells. Cytogenet. Genome Res., 104: 116-122.

Hombach-Klonisch, S., P. Pocar, J. Kauffold and T. Klonisch, 2006. Dioxin exerts anti-estrogenic actions in a novel dioxin-responsive telomeraseimmortalized epithelial cell line of the porcine oviduct. Toxicol. Sci., 90: 519-528.

Hong, H.X., Y.M. Zhang, H. Xu, Z.Y. Su and P. Sun, 2007. Immortalization of swine umbilical wein endothelial cells with human telomerase reverse transcriptase. Mol. Cells, 3: 358-363.

Jin, X., J.S. Lee, S. Kwak, S.Y. Lee and J.E. Jung et al., 2006. Establishment and characterization of three immortal bovine muscular epithelial cell lines. Mol. Cells, 21: 29-33.

Johnson, G.A., R.C. Burghardt, G.R. Newton, F.W. Bazer and T.E. Spencer, 1999. Development and characterization of immortalized ovine endometrial cell lines. Biol. Reprod., 61: 1324-1330.

Kasugai, S., N. Hasegawa and H. Ogura, 1990. A simple in vito cytotoxictity test using the MTT (3-(4,5)dimethylthiazol-2-yl)-2,5-diphenyl tetrazolium bromide) colorimetric assay: Analysis of eugenol toxicity on dental pulp cells (RPC-C2A). Jpn. J. Pharmacol., 1: 95-100.

Li, L., G. Willimsky, S. Seitz, Y. Xu, Y. Li, L.E. Schwarz, P.M. Schlag and T. Blankenstein, 2008. SV40 large T antigen-transformed human primary normal and cancerous mammary epithelial cells are phenotypically similar but can be distinguished in 3D culture with selection medium. Int. J. Cancer, 123: 1516-1525.

Masamune, A., M. Satoh, K. Kikuta, N. Suzuki and T. Shimosegawa, 2003. Establishment and characterization of a rat pancreatic stellate cell line by spontaneous immortalization. World J. Gastroenterol., 9: 2751-2758.

Matsumura, T., M. Takesue, K.A. Westerman, T. Okitsu and M. Sakaguchi et al., 2004. Establishment of an immortalized human-liver endothelial cell line with SV40T and hTERT. Transplantation, 77: 1357-1365.

May, T., P.P. Mueller, H. Weich, N. Froese, U. Deutsch, D. Wirth, A. Kroger and H. Hauser, 2005. Establishment of murine cell lines by constitutive and conditional immortalization. J. Biotechnol., 120: 99-110. 
Nakamura, H., F. Hiroko, H. Yuko, K. Tohru, N. Shigekazu, H. Michinari and I. Kanji, 2002. Establishment of immortal normal and ataxia telangiectasia fibroblast cell lines by introduction of the hTERT gene. J. Raduat. Res., 43: 167-174.

Oh, H.Y., X. Jin, J.G. Kim, M.J. Oh and X. Pian, 2007. Characteristics of primary and immortalized fibroblast cells derived from the miniature and domestic pigs. BMC Cell Biol., 8: 20-20.

Piao, C.Q., L. Liu, Y.L. Zhao, A.S. Balajee, M. Suzuki and T.K. Hei, 2005. Immortalization of human small airway epithelial cells by ectopic expression of telomerase. Carcinogenesis, 26: 725-731.

Pihan, G.A., A. Purohit, J. Wallace, H. Knecht, B. Woda, P. Quesenberry and S.J. Doxsey, 2003. Centrosome defects and genetic instability in malignant tumors. Cancer Res., 58: 3974-3985.

Putmann, S., V. Senner, S. Braune, B. Hillmann, R. Exeler, C.H. Rickert and W. Paulus, 2005. Establishment of a benign meningioma cell line by hTERT-mediated immortalization. Lab. Invest., 85: 1163-1171.
Qian, J.F., 2003. Domestic Animal Embryology. China Scientific and Cultural Publishing House China.

Satoru, K., N. Mitsuhiro, K. Tohru, M. Yoshiko and K. Taro et al., 2003. Successful immortalization of endometrial glandular cells with normal structural and functional characteristics. Am. J. Pathol., 163: 2259-2269.

Wen, J.D., H. Zhu, S. Murakami, P.C.K. Leung and C.D. MacCalman, 2006. Regulation of a disintegrin and metalloproteinase with thrombospondin repeats1 expression in human endometrial stromal cells by gonadal steroids involves progestins, androgens and estrogens. J. Clin. Endocrinol. Metab., 91: 4825-4835.

You, S., J.H. Moon, T.K. Kim, S.C. Kim and J.W. Kim et al., 2004. Cellular characteristics of primary and immortal canine embryonic fibroblast cells. Exp. Mol. Med., 36: 325-335.

Zhang, R., J. Gong, H. Wang and L. Wang, 2005. Bile salts inhibit growth and induce apoptosis of culture human normal esophageal mucosal epithelial cells. World J. Gastroenterol., 11: 6466-6471. 